\title{
Light Water Reactor Sustainability Constellation Pilot Project FY11 Summary Report
}

R. Johansen

September 2011

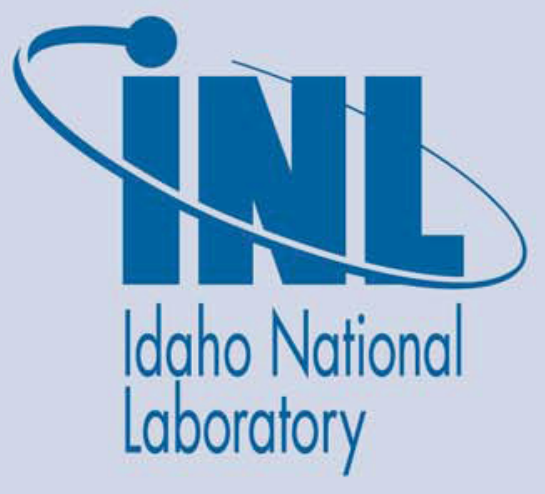

The INL is a U.S. Department of Energy National Laboratory operated by Battelle Energy Alliance 


\section{DISCLAIMER}

This information was prepared as an account of work sponsored by an agency of the U.S. Government. Neither the U.S. Government nor any agency thereof, nor any of their employees, makes any warranty, expressed or implied, or assumes any legal liability or responsibility for the accuracy, completeness, or usefulness, of any information, apparatus, product, or process disclosed, or represents that its use would not infringe privately owned rights. References herein to any specific commercial product, process, or service by trade name, trade mark, manufacturer, or otherwise, does not necessarily constitute or imply its endorsement, recommendation, or favoring by the U.S. Government or any agency thereof. The views and opinions of authors expressed herein do not necessarily state or reflect those of the U.S. Government or any agency thereof. 


\title{
Light Water Reactor Sustainability Constellation Pilot Project FY11 Summary Report
}

\author{
R. Johansen
}

September 2011

Idaho National Laboratory Idaho Falls, Idaho 83415

http://www.inl.gov

Prepared for the

U.S. Department of Energy

Office of Nuclear Energy

Under DOE Idaho Operations Office

Contract DE-AC07-05ID14517 



\section{CONTENTS}

ACRONYMS vii

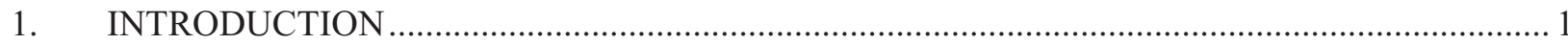

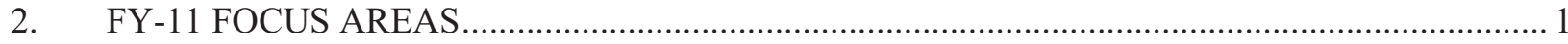

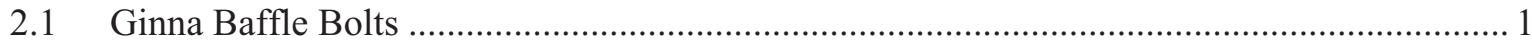

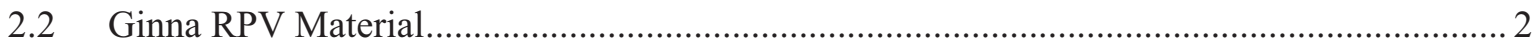

2.3 Ginna Reactor Vessel Internal Inspections ..................................................................... 2

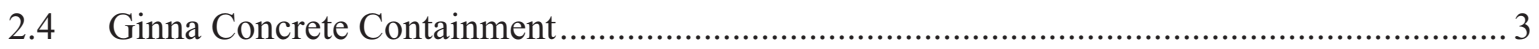

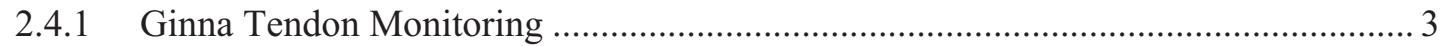

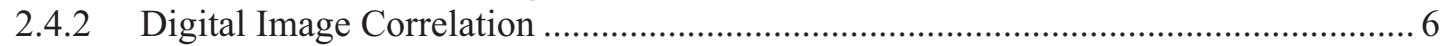

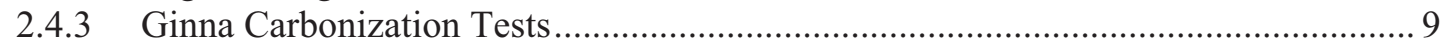

2.4.4 GinnaVisual Containment Inspection .............................................................. 9

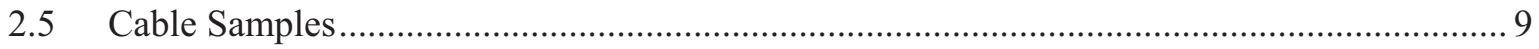

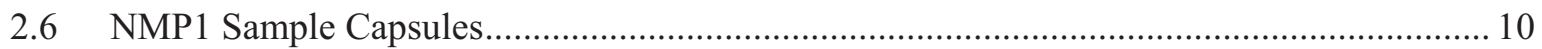

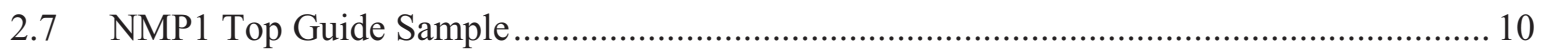

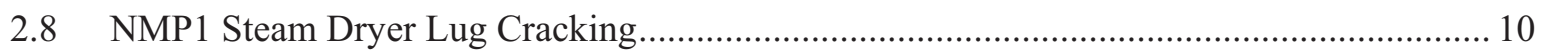

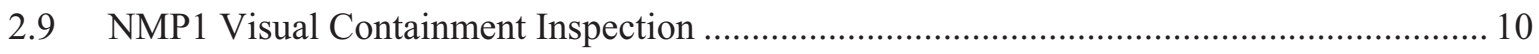

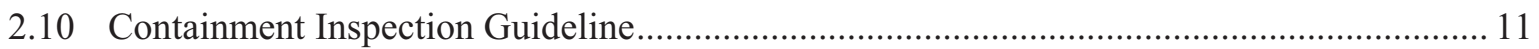

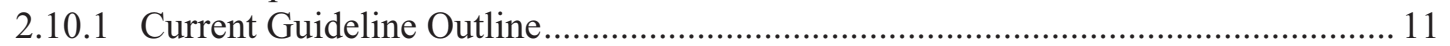

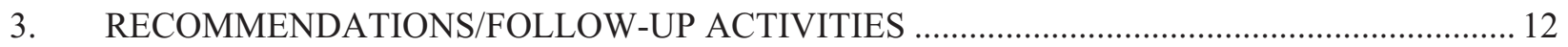

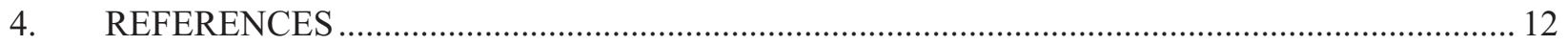

\section{FIGURES}

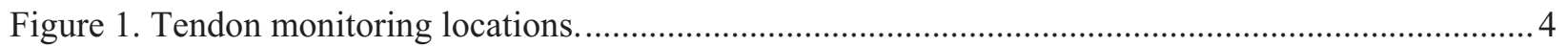

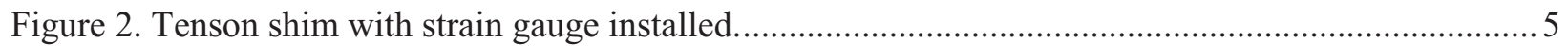

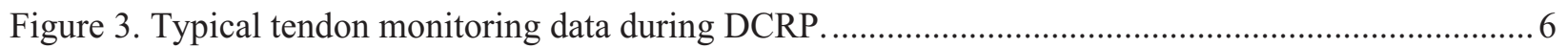

Figure 4. Digital image correlation camera setup at the 315 level........................................................ 7

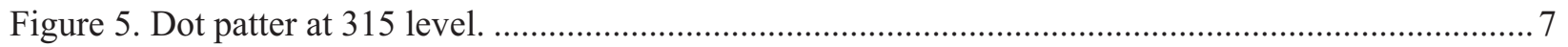

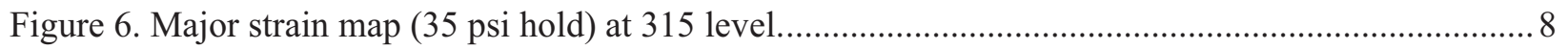

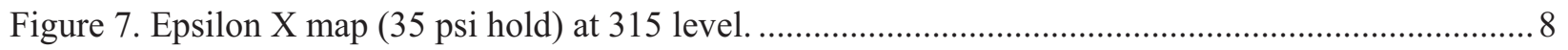

Figure 8. Epsilon Y map (35 psi hold) at 315 level.......................................................................... 


\section{ACRONYMS}

$\begin{array}{ll}\text { BWR } & \text { Boiling Water Reactor } \\ \text { CENG } & \text { Constellation Energy Nuclear Group } \\ \text { DIC } & \text { Digital Image Correlation } \\ \text { DOE } & \text { Department of Energy } \\ \text { EPRI } & \text { Electric Power Research Institute } \\ \text { Ginna } & \text { R.E. Ginna Nuclear Power Plant } \\ \text { IASCC } & \text { Irradiation-Assisted Stress Corrosion Cracking } \\ \text { INL } & \text { Idaho National Laboratory } \\ \text { ISP } & \text { Integrated Surveillance Program } \\ \text { LTO } & \text { Long Term Operation Program (EPRI) } \\ \text { LWRS } & \text { Light Water Reactor Sustainability Program (DOE) } \\ \text { MAaD } & \text { Materials Aging and Degradation Pathway in LRWS } \\ \text { NMP1 } & \text { Nine Mile Point Unit 1 Nuclear Power Plant } \\ \text { ORNL } & \text { Oak Ridge National Laboratory } \\ \text { PWR } & \text { Pressurized Water Reactor } \\ \text { RPV } & \text { reactor pressure vessel }\end{array}$




\section{Light Water Reactor Sustainability Constellation Pilot Project FY11 Summary Report}

\section{INTRODUCTION}

As a partner in research for operations beyond 60 years, Constellation Energy Nuclear Group (CENG), has volunteered two of its nuclear power plants: R. E. Ginna and Nine Mile Point Unit 1 (NMP1). The coordinated work to be performed with CENG is a joint effort involving the Electric Power Research Institute (EPRI) Long Term Operation (LTO) Program and the Department of Energy (DOE) Light Water Reactor Sustainability (LWRS) Research \& Development Program. The following report summarizes the activities performed in FY11 at Ginna and NMP1 power plants.

The R. E. Ginna nuclear power plant is located on Lake Ontario approximately 20 miles from Rochester, NY. The $581 \mathrm{MW}$ capacity unit is a pressurized water reactor (PWR) which began commercial operation in 1970. The Nine Mile Point Unit 1 (NMP1) nuclear power plant is located on Lake Ontario approximately 40 miles from Syracuse, NY. The 620 MW capacity unit is a boiling water reactor (BWR) which began commercial operation in 1969. Both units have entered into their 60 year license renewal period, which makes them ideal units to gain further insight into the potential issues for license renewal beyond 60 years.

The following report summarizes the activities in focus areas performed from October 1, 2010 through September 30, 2011 (FY11) at Ginna and NMP1 power plants.

\section{FY11 FOCUS AREAS}

\subsection{Ginna Baffle Bolts}

The core baffle is comprised of vertical plates surrounding the peripheral fuel assemblies that direct coolant through the core. The vertical plates are bolted to the edges of the horizontal former plates that bolt to the inside surface of the core barrel. The bolts that secure the baffle plates to the former plates are referred to as the baffle former bolts or baffle bolts.

Material degradation of the baffle-former bolts has been identified as a reactor vessel internals aging issue since the 1980s. In 1999, the utility operating Ginna Station (Rochester Gas and Electric) was acting in a proactive manner relative to potential cracking due to SCC and IASCC, as well as other possible degradation mechanisms. The original baffle-former bolt material is Type 347 stainless steel, which some data suggest could have a more pronounced susceptibility to damage than other stainless steels. Cracking of the bolts generally will occur at the shank to bolt head interface, which makes it impossible to see using visual testing (VT) methods since the head is captured with a weld and locking cup. Therefore, current guidance is to use ultrasonic testing (UT) methods to inspect $100 \%$ of the accessible bolts or justify a plant-specific plan, such as using a minimum integrity bolt pattern.

As result of the industry-wide programs on baffle bolt cracking, the Ginna plant replaced 56 baffle bolts in 1999. Some bolts were sent out for evaluation, resulting in approximately 42 bolts left on location at the plant site. As part of the aging management plant for Ginna, approximately 180 bolts were anticipated to be replaced during Spring 2011 outage to ensure the minimum bolting pattern to assure structural integrity under limiting operating conditions. The higher fluence baffle bolts from the 2011 replacement were identified as potential candidates for use in the MAaD pathway studies. However, the bolt material is 347 stainless steel which is not as ideal as 316 stainless steel for the studies.

The original spring 2011 schedule anticipated replacement of 18 bolts per day. However, bolt replacement during the outage proved to be significantly more difficult than anticipated. Only 28 bolts were removed and 3 could not be replaced. Bolt replacement was activities were stopped and a recently developed ultrasonic approach was implemented. 
A probe design by Areva and used in Germany was successfully demonstrated at the Areva Lynchburg, VA site to have a $90 \%$ confidence level for detection. Ninety-eight original bolts with the internal curved hex-head design were inspected using this probe design and ninety-seven were found acceptable with no indications. Additionally, UT was performed on twenty-four of the removed bolts on the back-side, and no indications were identified. One hundred twenty-one of one hundred twenty-two bolts were found to be acceptable. This integrity assessment met an acceptable minimum bolting pattern confirmed by Westinghouse, in which the three missing bolts included in the evaluation.

The difficulty encountered during the bolt replacement has developed renewed interest in the baffle bolt replacement guidelines. Although the new probe design utilized at Ginna was successful, the use of welded cross bars limits access to the socket for other plant designs. Additionally, long term behavior of the baffle bolts may need to be better understood to support extended operation beyond 60 years.

Therefore, further evaluation is recommended to develop a path forward for baffle bolt study. This evaluation is anticipated to be performed early in FY12 with a shipment of baffle bolts to follow.

\subsection{Ginna RPV Material}

Ginna has a surveillance program that has tested five capsules through the current time period. The last tested capsule had a fluence of about $6 \times 10^{19} \mathrm{n} / \mathrm{cm}^{2}$, which represents licensed life out to about 60 years of operation at the inside surface of the RPV wall for the most limiting material. Collection of broken irradiated test specimens from the tested capsules stored at the Westinghouse hot cell facility currently was pursued for shipment to ORNL for microstructure studies under the MAaD Pathway. The following specimens have been identified to be shipped:

\section{Capsule T}

Broken HAZ Charpy specimen halves from IDs H21 - H30

Broken forging Charpy specimen halves from IDs P21-P30

\section{Capsule S}

Broken HAZ Charpy specimen halves from IDs H31-H42

Broken forging Charpy specimen half from IDs P31- P42

\section{Capsule $\mathbf{N}$}

Broken HAZ Charpy specimen halves from IDs H43 - H54

Broken forging Charpy specimen half from IDs P43 -P54

In FY11 the capsule $\mathrm{N}$ specimens have been shipped. The remaining sample shipments will occur early in FY12.

\subsection{Ginna Reactor Vessel Internal Inspections}

The following reactor vessel internal inspections and replacements were monitored as part of the Ginna Spring 2011. These inspections were based on MRP-227 and in service inspections (ISI) per ASME Code Secion XI:

- Baffle-former bolts (discussed previously)

- Baffle-former assembly

- Baffle former edge bolts

- Lower guide tube flange weld

- Upper core barrel flange to shell weld

- Thermal shield flexures

- Control rod guide cards 
- X750 split pin replacement

- Lower core plate and fuel pins.

These examinations were completed with no findings or areas which may require further assessment as part of the LWRS program.

\subsection{Ginna Concrete Containment}

Concrete monitoring at Ginna was focused on augmented tests which can be deployed with available technology. The augmented testing included:

- Tendon Monitoring

- Digital Image Correlation

- Carbonization Testing.

These tests and results are discussed in detail in Reference 2.

\subsubsection{Ginna Tendon Monitoring}

The cylindrical containment wall is pre-stressed with 160 vertical tendons within the wall of the containment that are equally spaced circumferentially around the containment. At penetrations in the containment (e.g. equipment hatch), the tendons are curved around the penetrations. These tendons are incorporated into the containment design in order to keep the cylindrical containment walls in compression during an internal pressurization.

Twenty of the vertical tendons and one exposed circumferential rebar were outfitted with a fiber optic strain gauges (Figures 1 and 2) connected to a Data Acquisition System (DAS) to monitor temperature and strain of the containment wall and tendons. The system was operational for approximately one month prior to the Integrated Leak Rate Test (ILRT) and remains operational. The tendon monitoring system provides an active method to monitor and trend containment health. Testing of the tendon monitoring system showed proper responses to the containment pressurization. See Figure 3.Continuation of monitoring and evaluation of this system is recommended for FY12. 


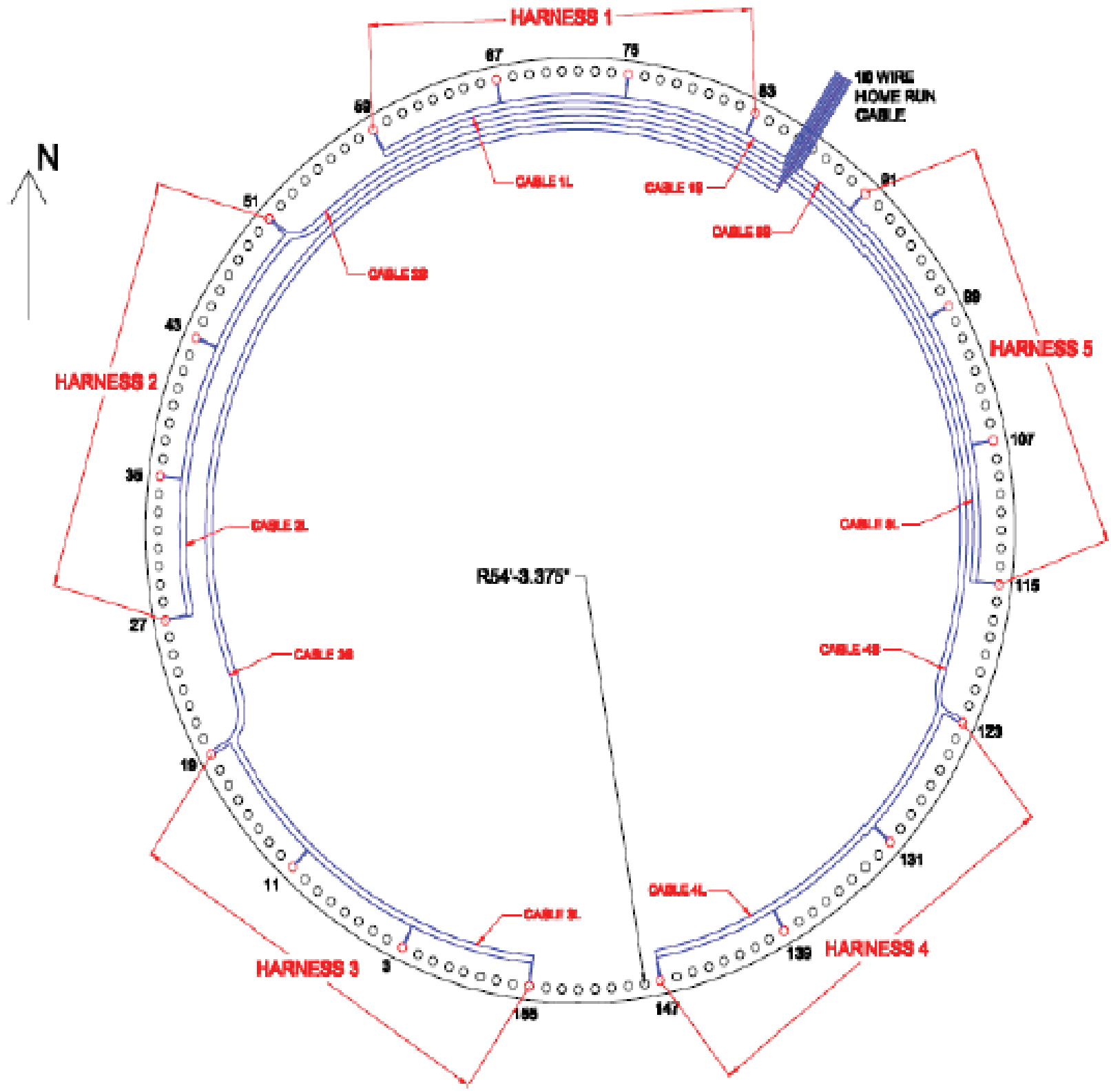

Figure 1. Tendon monitoring locations. 


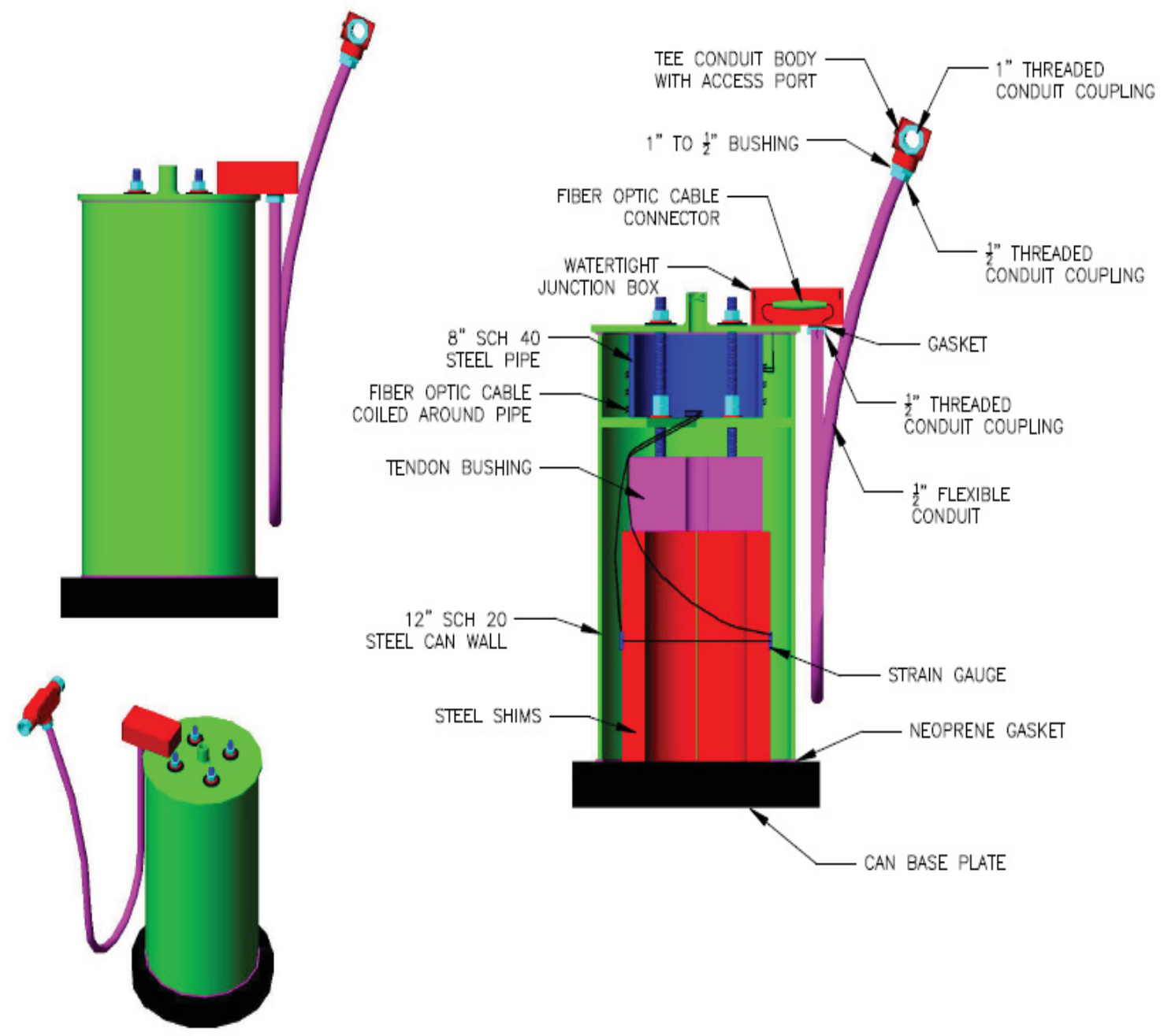

Figure 2. Tenson shim with strain gauge installed. 


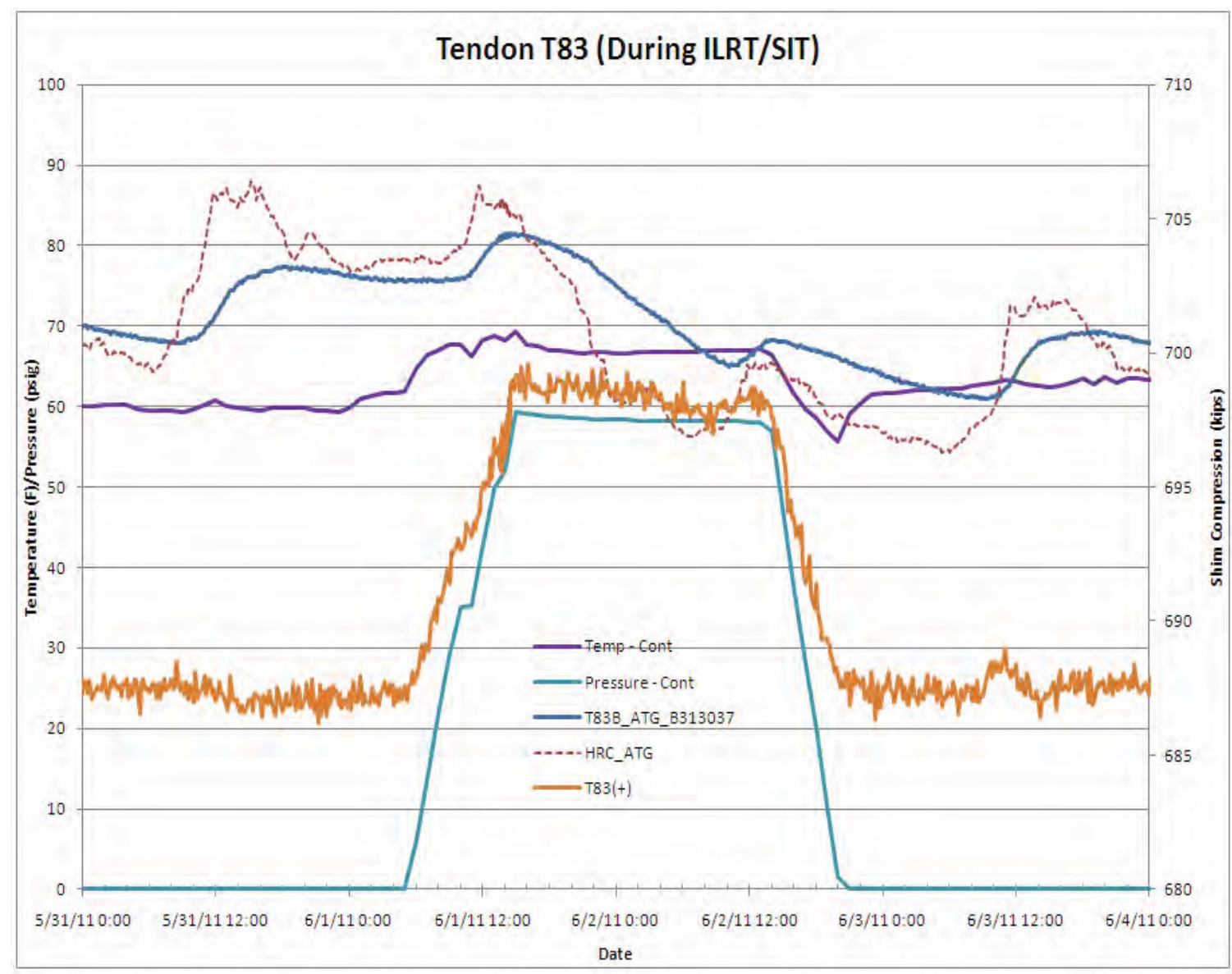

Figure 3. Typical tendon monitoring data during DCRP.

For additional information on the tendon monitoring system and testing results refer to Reference 2 .

\subsubsection{Digital Image Correlation}

Digital Image Correlation (DIC) utilizes two cameras separated on a bar at a known distance. The cameras capture a pattern on the surface and the software defines the shape of the surface. Utilizing multiple images, the software analyses shape changes and defines strain and displacements occurring on the surface. These images can be utilized for definition of shape changes for detection and monitoring of degradation mechanisms. See Figures 4 and 5 for the test set up. 


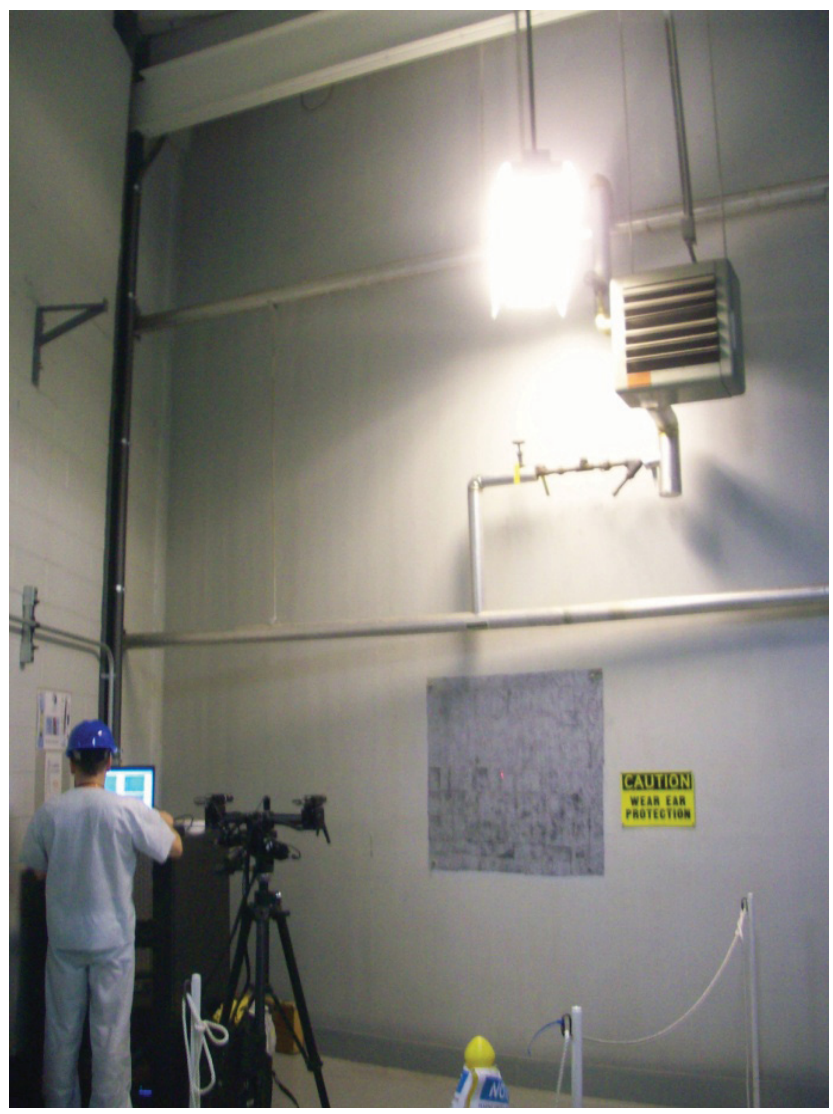

Figure 4. Digital image correlation camera setup at the 315 level.

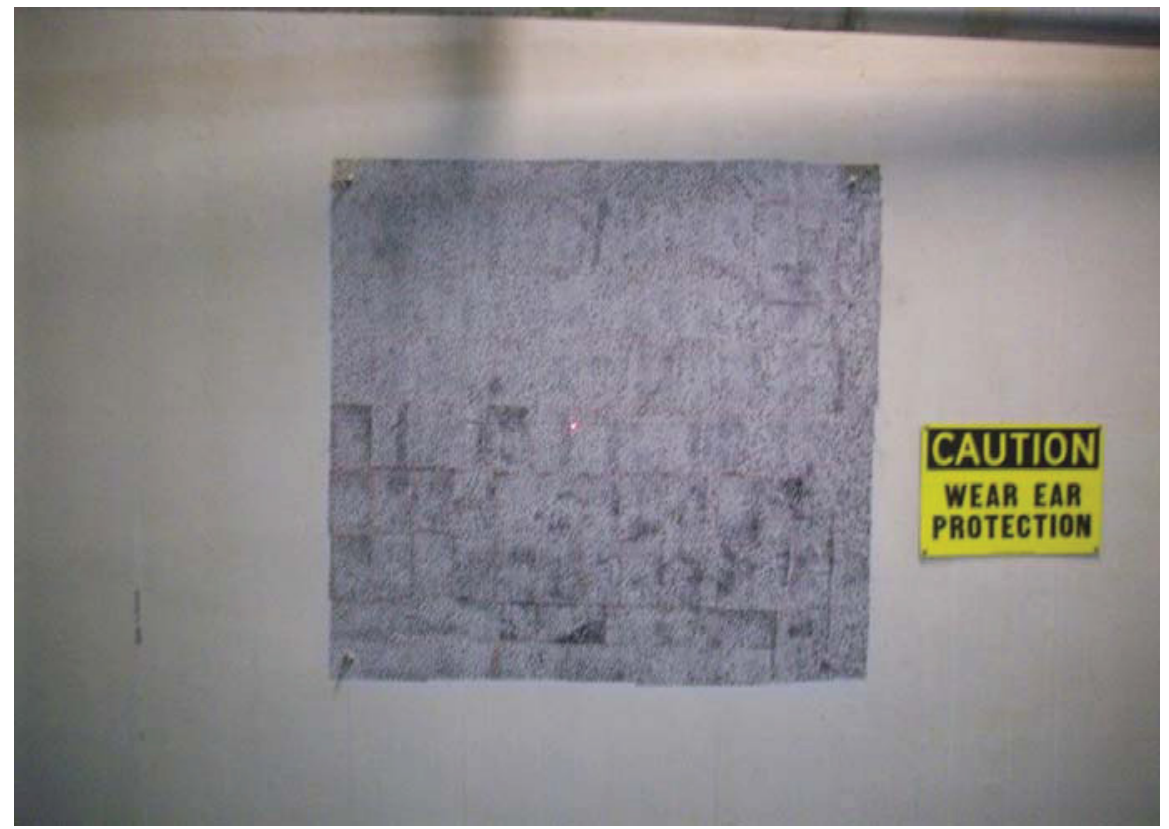

Figure 5. Dot patter at 315 level. 


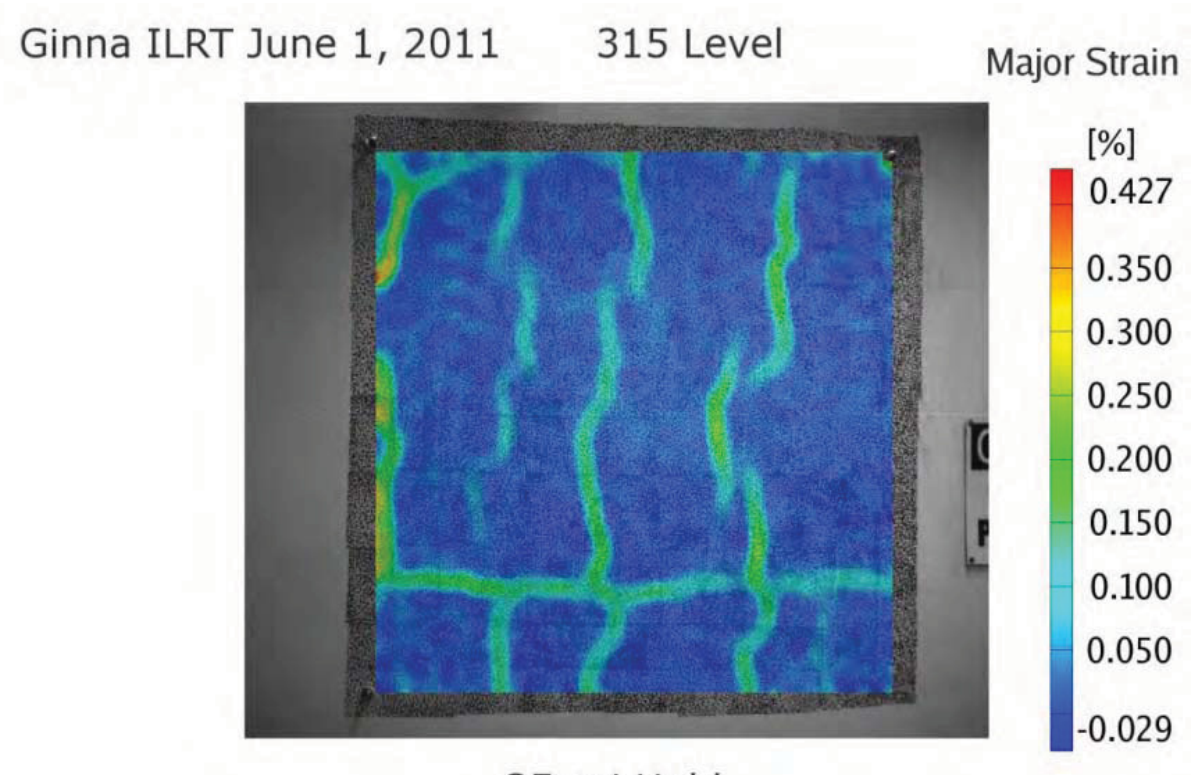

35 psi Hold

Figure 6. Major strain map (35 psi hold) at 315 level.

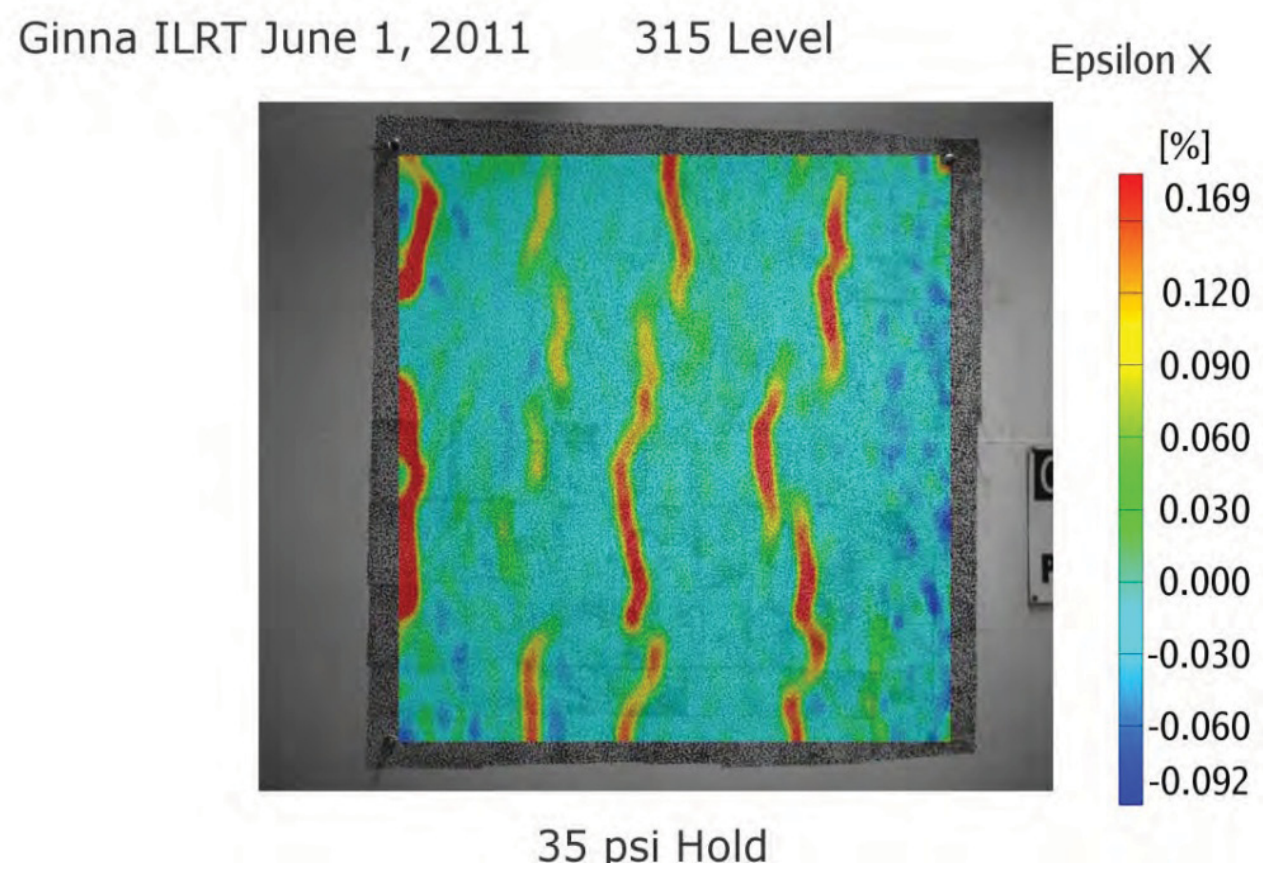

Figure 7. Epsilon X map (35 psi hold) at 315 level. 


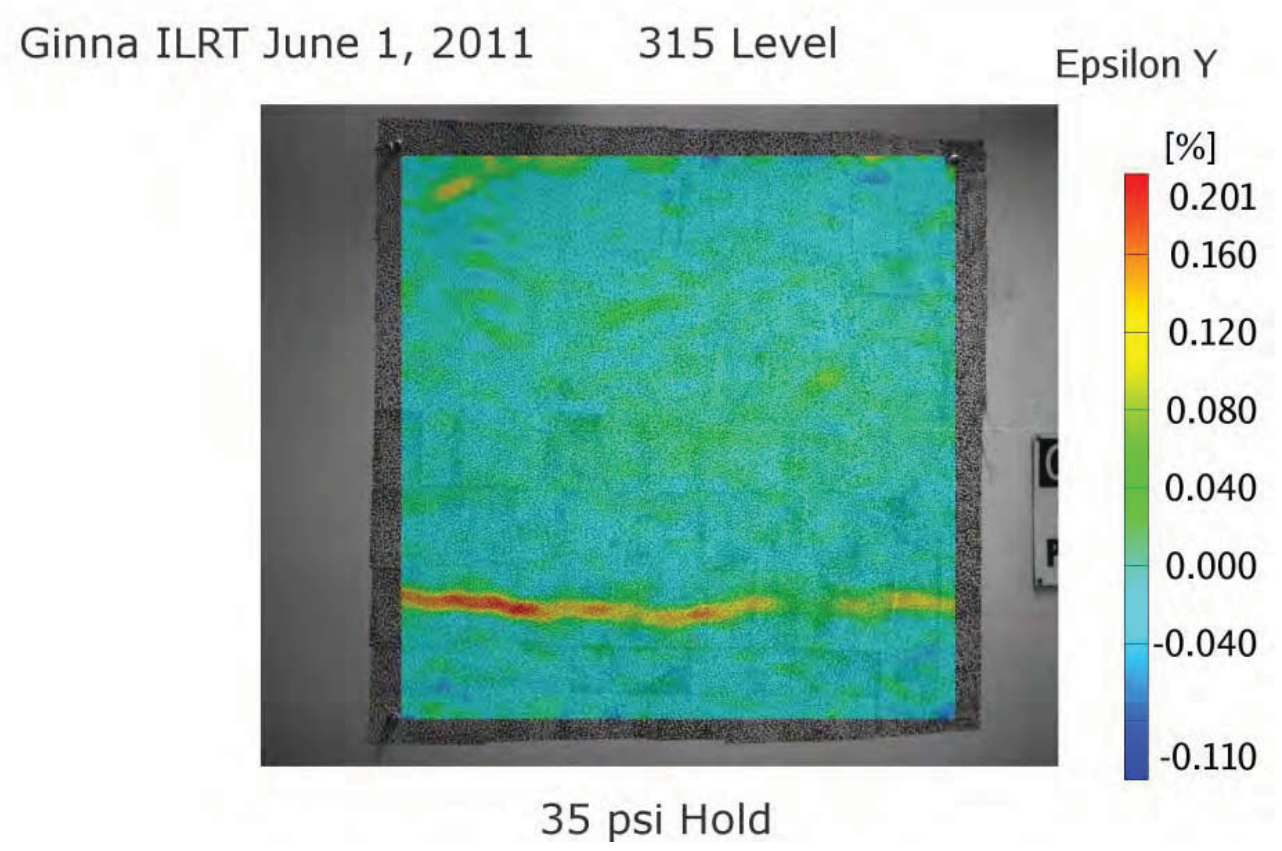

Figure 8. Epsilon Y map (35 psi hold) at 315 level.

Two 3D digital image correlation systems were utilized during the Ginna ILRT. The most comprehensive data was obtained at the personnel hatch location, where a system continuously acquired data throughout the complete pressurization and depressurization cycles. Displacements and strains were also recorded periodically at a location at the 315 level and near the equipment hatch. These three locations were permanently marked as monitoring locations. Measurements included radial and in-plane displacements, principal strains, and crack opening displacements. See Figures 6, 7, and 8 for typical DIC results. Data was also obtained near the equipment hatch; the sensor was brought there for each of the three pressure holds.

For additional information on the digital image correlation testing refer to Reference 2.

\subsubsection{Ginna Carbonization Tests}

Carbonization testing detects the chemical reaction of hydrated Portland cement with carbon dioxide in the air. Carbonation which is normally limited to the surface layer causes reduction in $\mathrm{pH}$ and exposes the rebar to corrosion. Testing at Ginna was accomplished by collecting particles from drilling a small hole and checking the PH. A reduced PH indicates carbonization and a deeper sample was collected and tested. The process was repeated until carbonization was not detected. Testing at Ginna showed carbonization was less than the rebar depth at the locations monitored.

\subsubsection{GinnaVisual Containment Inspection}

A walk down and visual inspection was performed with Ginna personnel concentration on exposed sections of the containment liner, the bottom of the pressurizer support area and accessible portions of the outboard side of the reactor vessel concrete support structure. The visible portions of the liner and structural concrete appeared free of significant active degradation.

\subsection{Cable Samples}

If available samples of cables replaced for aging studies were to be collected. The cables needed to be under known environmental condition such as wetted. Replacement of cables of interest were not available during FY11. 


\subsection{NMP1 Sample Capsules}

NMP1 has two supplemental surveillance capsules that were inserted. These capsules have irradiated materials from the previously tested capsules plus non-irradiated base metal from the plant archives that represents the actual material in the RPV; they also are located in positions that have higher lead factors than typical BWRs. Neither of these two capsules are part of the Integrated Surveillance Program (ISP) that the BWRVIP has instituted, so there is no industry plan to test these capsules. However, if the projected fluences are high enough to provide data associated long term operation, testing of the materials in the two capsules could be useful to assess the embrittled conditions for BWRs. Even though the maximum fluence at 80 years of operation may approach the fluence for PWRs early in plant life, the issues of different neutron fluxes and irradiation temperatures can be important. However, preliminary evaluations indicate that the samples need to stay in the reactor longer to reach higher fluence levels before any action is taken.

\subsection{NMP1 Top Guide Sample}

NMP1 has found cracking in the top guide plate similar to that at the Oyster Creek Nuclear Power Plant. The 304 stainless steel top guide plates hold the fuel clusters in position. At Oyster Creek several $3 \times 7$ inch samples were removed from the top guide and were evaluated under the Cooperative IASCC Research (CIR) Program, which is an international research effort designed to address irradiation-assisted stress corrosion cracking (IASCC) in light water reactor components. The results of the study were published in EPRI 1014511 and concluded that IASCC most likely played a role in the initiation and/or propagation of the cracking. However, additional study of the intergranular cracking was suggested to further define the root cause.

The proposed work at NMP1 was to take similar samples as previously obtained from Oyster Creek. These samples would further support the work previously performed and would be of general interest to the industry in support of understanding IASCC in an area of low apparent stress. Several top guide cracks at NMP1 have been identified and are being periodically monitored for crack growth, similar crack locations to those at Oyster Creek are being considered for sampling. Repair of the sample locations would not be necessary based on analyses previously performed at Oyster Creek.

The ideal time for obtaining the samples would have been the Spring 2011 outage. However, the preliminary cost estimates for a subcontractor sample the top guide was prohibitive.

The inspection results from the Spring 2011 examinations did show that some of the indications identified in 2005 are getting larger. The final inspection reports were not available for confirmation and the results will be verified when possible. Evaluation of the cost and benefit of top guide samples to further understand the mechanism of degradation needs to be performed prior to pursuing samples further.

\subsection{NMP1 Steam Dryer Lug Cracking}

Indications were identified during the visual inspections of the steam dryer support brackets (or lugs). These indications led to subsequent supplementary UT examination to verify the extent and validity of the cracking indications. The support brackets had been previously inspected in 2001 using a similar inspection technique without any reportable indications being found. A flaw evaluation and crack growth analysis conservatively estimated that the lugs are acceptable for at least on more operating cycle. This may be an area for future evaluations and study.

\subsection{NMP1 Visual Containment Inspection}

A walk down and visual inspection was performed with NMP1 personnel concentration on accessible areas of the torus externals and torus room. The inspection included the torus room concrete walls and floor and was conducted from the floor elevation. Therefore, the top of the torus, the drywell ventpipes, and the torus room ceiling were not included in the inspection. 
The inspection showed the general condition of the torus structure and concrete room to be acceptable. Areas showing degradation are not progressing at an excessive rate and the existing programs are adequate to monitor and manage the condition of the torus as it ages.

\subsection{Containment Inspection Guideline}

The Containment Inspection Guideline is to provide a methodology for the performance of augmented containment structures inspections. The objective is to provide a basis for the long term operation of the containment beyond 60 years. This guide will not overlap with current containment periodic inspection programs, or overlap with currently required inspections to meet license renewal activities, to avoid repetition.

The scope of the augmented inspection includes the containment cylindrical wall, dome, foundation, liner, mechanical penetration, equipment and personnel hatches, fuel pools, vessel shield wall, sumps, drywell, and torus structure.

\subsubsection{Current Guideline Outline}

1. Objective.

2. Containment function and physical description (PWR and BWR).

3. Scope (concrete, steel structures, steel reinforcement, liner, studs, tendons, rock anchors, piles, metallic penetrations, and embedments. Electrical penetrations will be excluded from the scope as these can be more easily replaced.)

4. Existing Code requirements for inspection (ASME Section XI IWE/IWL), review current state of industry practice (EPRI, NUREG's).

5. Degradation Mechanisms (the augmented inspections will all be degradation mechanism based. The degradation mechanisms for concrete, steel, and any other materials will be provided).

6. Assessment of adequacy of current inspection requirements, compared to degradation mechanisms. (The tabulation will include what coverage is provided by the current inspections and define what coverage is anticipated to be provided by the augmented coverage). Develop recommendations for augmenting the inspection plans.

7. Monitoring recommendations including strain gauge instrumentation of tendons, strain instrumentation of concrete and rebar, and concrete surface configuration tracking using DIC will be defined. Investigate methods for foundation (pile inspections).

8. Develop recommendations for non-destructive inspection of liners (PWR) and Drywell (BWR) in regions that are deemed inaccessible, in combination with foundation inspection. Perform proof of concept at Pilot Plants. Work to include use of strain measurements, corrosion mapping techniques, and structural integrity assessment (foundation piles) in inaccessible regions.

A draft of the Containment Inspection Guideline will be complete at the end the fiscal year 2011 (September 30,2011) The draft will be based on the work completed in FY09 and FY10 at the R.E. Ginna and Nine Mile Point Unit 1 stations. 
The proposed FY12 work will focus on the inside containment condition assessment at Ginna and extended review of activities on the torus at Nine Mile Point. This will include preparation for the Ginna 2012 outage and careful consideration of the in-containment structures. A critical part of the inside containment structure is the liner. This is generally welded steel plates that are leak tight and provide an inner form for the concrete containment. The liner is generally attached to the concrete with angles or studs. The liner is frequently insulated inside the containment. The liner also generally passes into regions that are below the level of floors inside the containment. This makes the liners "inaccessible" for inspection. These inaccessible regions have been the location of corrosion and liner thinning. It is the intent to consider inspection of the region of the liner up to 12 inches below the floor level. Potential techniques for inspection include ultrasonic-based techniques such as guided wave, synthetic aperture focusing technique (SAFT). Non-UT techniques will also be considered. The guideline will be updated based on the investigative work to identify a methodology for baseline inspections.

Lessons learned from the Ginna Tendon Monitoring System installed in FY11 will be analyzed and factored into methodologies proposed to trend instrumentation data.

\section{RECOMMENDATIONS/FOLLOW-UP ACTIVITIES}

Based on the FY11 activities and discussions with CENG and EPRI personnel the following activities include:

- Evaluation of the path forward for the Ginna Baffle bolts. This will include the industry perspective based on long-term operation and the LWRS MAaD pathway goals.

- Continuation of tendon monitoring data collection. After one year of operation the data shall be evaluated for trends and sensitivity to environmental conditions.

- Evaluation and planning for the next outages at Ginna and NMP1 for participation opportunities. The outages occur in FY13 but identification activities needs to occur within the next few months to ensure inclusion in the outage schedule if necessary.

- Evaluation of the NMP1 top guide assembly sampling for cost and benefit and potential LWRS applicability.

- Monitoring of the development for NMP1 steam dryer lug cracking for potential LWRS applicability.

- Continuation of the Containment Inspection Guideline.

- Evaluate non-destructive methods for containment liner inspections.

\section{REFERENCES}

1. William L. Server and Jeff Gilreath, (ATI Consulting), 2011, Reactor Vessel Internals Inspection Results from Recent Examinations at Ginna and Nine Mile Point Unit 1, September 2011.

2. Lucius Pitkin, Inc., 2011, Containment Tendons, Rebar, and Concrete Augmented Inspection Results, A10551-R003, Rev. 0, June 2011. 